\title{
A população da cidade de São Gabriel, RS e o grau de satisfação em relação à qualidade ambiental urbana
}

\author{
The population of São Gabriel city, RS and satisfaction level in relation to urban \\ environmental quality
}

\section{Daniel Dejalmiro Medeiros da Silva, Nara Rejane Zamberlan dos Santos, Hamilton Munari Vogel e Mirla Andrade Weber}

Unipampa campus São Gabriel, RS, Brasil

thisdaniels@gmail.com; narazamberlan@gmail.com; hamiltonvogel@unipampa.edu.br; mirlaweber@unipampa.edu.br

\section{Resumo}

O crescimento de impactos ambientais nas cidades é proveniente do aumento da população e da constante ampliação de áreas urbanas. Esses conflitos somados à falta de infraestrutura contribuem para a deterioração da qualidade ambiental e de vida da população urbana e, consequentemente, para as alterações fisicas, químicas e biológicas que comprometem ecossistemas e modificam a paisagem nesses centros. A temática do presente estudo relaciona-se com a percepção e satisfação da qualidade ambiental urbana tendo, como atores sociais, os residentes de uma amostra da população de cinco bairros no município de São Gabriel, RS. Através de entrevistas foram abordados temas, tais como, resíduos sólidos, poluição sonora, visual, do ar, do solo, desmatamento, presença de esgoto, ocupação irregular, enchentes, limpeza urbana e políticas ambientais municipais. O resultado da pesquisa demonstrou satisfação com alguns aspectos ambientais, mas insatisfação com as politicas públicas indiferentes à qualidade de vida dos cidadãos.

Palavras-chave: Sociedade. Meio ambiente. Intervenção antrópica.

\begin{abstract}
The growth of environmental impacts in the cities comes from the increase in population and the constant expansion of urban areas. These conflicts coupled with the lack of infrastructure contribute to the deterioration of environmental quality and life of the urban population and consequently to the physical, chemical and biological changes that compromise ecosystems and alter the landscape in these centers. The theme of this study relates to the perception and satisfaction of urban environmental quality has, as social actors, residents of a sample of the population of five districts in São Gabriel, RS. Through interviews addressed issues such as solid waste, noise, visual, air, soil, deforestation, the presence of sewage, illegal occupation, floods, urban sanitation and municipal environmental policies. The result of the survey showed satisfaction with some environmental aspects, but dissatisfaction with public policy indifferent to the quality of life of citizens.
\end{abstract}

Keywords: Society. Environment. Human intervation. 


\section{Introdução}

A urbanização se reflete em questões ambientais, pois o crescimento rápido e isento de planejamento tem contribuído para a deterioração dos espaços urbanos, gerando problemas de ordem social, econômica e ambiental.

Sendo assim, as condições ambientais desempenham papel importante na determinação das condições de vida, principalmente na proteção à saúde, que resulta dos serviços de esgotamento sanitário, aporte adequado de água, coleta de lixo, dentre outros que, se não tratados com dada importância geram desequilíbrios em vários níveis, danos à natureza - como o desmatamento e queimadas - além, de problemas característicos do ambiente urbano, como poluição oriunda de ação antrópica.

Para Fernandez (2004) as alterações ambientais ocorrem por inumeráveis causas, muitas denominadas naturais e outras oriundas de intervenções antropológicas, consideradas não naturais. É fato que o desenvolvimento tecnológico contemporâneo e as culturas das comunidades têm contribuído para que essas alterações no e do ambiente se intensifiquem, especialmente no ambiente urbano.

A elevada intensificação do processo de urbanização não vem acontecendo somente nas grandes cidades, mas atinge também as pequenas cidades conforme Brilhante (2000), mostrando-se cada vez mais como um grave vetor de problemas ambientais e sociais.

Apesar da importância dos Planos Diretores que estabelecem os requisitos necessários para 0 cumprimento da função social da propriedade -, como instrumentos para nortear o desenvolvimento e a expansão urbana, unicamente, os mesmos não se mostram capazes de resolver os problemas provenientes do gerenciamento do território urbano.
De acordo com Sachs (2007, p. 47) na recuperação urbana as medidas de melhoria do meio ambiente urbano deveriam ocupar lugar importante e estratégico nos planos de desenvolvimento, pois a questão ambiental deve ser compreendida como um produto da intervenção da sociedade sobre a natureza. Diz respeito não apenas a problemas relacionados à natureza, mas às problemáticas decorrentes da ação social, segundo Rodrigues (1998). Não há como discutir qualidade ambiental sem considerar os valores sociais da população.

Tuan (1983), por sua vez, relata que é preciso conhecer a qualidade e a intensidade da experiência do homem com o ambiente para se conhecer a identidade do lugar. De modo especial, torna-se fundamental o estudo da qualidade ambiental urbana pelo viés da percepção dos moradores, haja vista que parte dos problemas ambientais observados está associada aos impactos dos processos de urbanização e das atividades em meio urbano, tornandose foco de atenção na atualidade por mostrarem um quadro evolutivo de agravamento e fazerem parte do rol de preocupações da sociedade (CARVALHO, 2007).

Os termos "sustentabilidade" e “desenvolvimento sustentável" estão associados às dimensões econômicas, ambientais e sociais. Esta ideia é reforçada por Alirol (2001), ao dizer que os atores veem os problemas ambientais de forma diferente, conforme a categoria social e a profissão à qual pertencem.

Nesse contexto, o estudo da percepção ambiental é de fundamental importância, pois por este meio é possível conhecer a cada um dos grupos envolvidos, facilitando a realização de um trabalho com bases locais, partindo da realidade do público alvo, para conhecer como os indivíduos percebem o ambiente em que convivem, suas fontes de satisfação e insatisfação (FAGGIONATO, 2007).

A percepção ambiental é considerada um processo principalmente cognitivo, que se dá através de 
mecanismos perceptivos propriamente ditos a partir da captação dos sentidos durante a interação entre o indivíduo e o ambiente. Dessa forma, as percepções passam a ser subjetivas para cada indivíduo, mesmo diante de elementos comuns (DEL RIO, 1999).

Nesse viés, o estudo da percepção ambiental refere-se às questões de como o ambiente é apresentado e compreendido pelo ser humano. Logo tem uma importância básica para que possamos compreender as inter-relações entre e os seres humanos e o meio ambiente, suas expectativas, satisfações, anseios, valores, critérios de julgamentos e condutas, visto que cada ser percebe, julga e age diferentemente face à problemática ambiental, reage e responde frente às ações sobre o meio e as respostas ou manifestações são, portanto, resultado das percepções, dos processos cognitivos, julgamentos e expectativas de cada indivíduo. (FAGGIONATO, 2007).

Assim, como resultado da percepção, uma melhoria da qualidade ambiental urbana seria visível se diretamente ligada à consciência da sociedade sobre as formas de manutenção e uso do ambiente onde se vive e do emprego de hábitos culturais mais saudáveis. Macedo (1991) apud Mazzeto (2000) afirma que a qualidade ambiental de um ecossistema expressa as condições e os requisitos básicos que ele detém, de maneira física, química, biológica, social, econômica, tecnológica e política.

Muitos fatores contribuem para os impactos ambientais negativos nos centros urbanos. Como resultado direto do crescimento populacional e do avanço da urbanização não planejada o presente trabalho visa verificar o grau de satisfação dos moradores de São Gabriel quanto à qualidade ambiental do município.

\section{Material e Métodos}

O presente estudo realizou-se através uso de técnicas de coleta de informações baseada em fontes primárias e secundárias. O levantamento de dados secundários caracterizou-se por pesquisa bibliográfica. As informações obtidas de ordem primária referem-se ao resultado do trabalho de campo realizado em cinco bairros do município de São Gabriel, Rio Grande do Sul. Através da aplicação de um instrumento de pesquisa estruturado com 13 questões, foi avaliada a percepção ambiental dos entrevistados e seu grau de satisfação quanto aos aspectos ambientais tais como, resíduos sólidos, poluição sonora, visual, do ar, do solo, desmatamento, presença de esgoto, ocupação irregular, enchentes, limpeza urbana e a aplicação de políticas ambientais municipais que explanam um panorama geral do grau de satisfação dos moradores de São Gabriel - RS. Dada às inúmeras variáveis passíveis de análise foram selecionados aspectos relacionados com a poluição, qualidade da água e outros fatores antrópicos, mesmo considerando a dificuldade em selecioná-los e a interação entre os mesmos.

A definição dos locais de pesquisa foi proposta de acordo com o grau do desenvolvimento de urbanização dos bairros pertencentes ao município, tendo como base o sentido Centro - Bairro. A partir deste pressuposto, foram definidos cinco locais, denominados bairros Centro, Capiotti, Cidade Nova, Independência e Mato Grosso, como ilustra a Figura 1.

O Quadro 1 apresenta os cinco bairros estudados, suas localizações em relação ao bairro Centro e os respectivos números de entrevistados. 


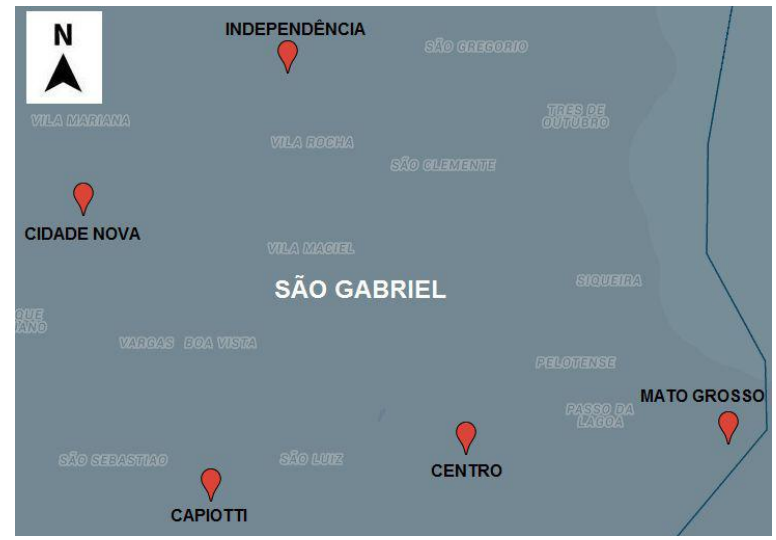

Figura 1 - Localização dos cinco locais de estudo no município de São Gabriel, RS.

Fonte: Google Maps, com adaptações feitas pelo autor, 2015

Quadro 1 - Dados informacionais sobre os locais estudados, suas localizações em relação ao bairro Centro e número de entrevistados

\begin{tabular}{|c|c|c|}
\hline Bairro & Localização & $\begin{array}{c}\mathbf{N}^{\mathbf{0}} \text { de } \\
\text { entrevistados }\end{array}$ \\
\hline Capiotti & Sudoeste & 40 \\
\hline Centro & Centro & 40 \\
\hline Cidade Nova & Oeste & 40 \\
\hline Independência & Norte & 40 \\
\hline Mato Grosso & Leste & 40 \\
\hline \multicolumn{3}{|c|}{ Fonte: Autor, 2015 }
\end{tabular}

A definição da população entrevistada foi baseada no método proposto por Barbisan et al. (2009) com adaptações pertinentes aos locais de pesquisa.

Tomou-se como foco o centro do local e arbitrou-se um raio mínimo e máximo de distância para estabelecer a abrangência da coleta de dados. Estes raios compreendem uma primeira faixa de 100 metros e uma segunda faixa de 200 metros de distância do ponto central.

Após a coleta, que ocorreu entre os meses de fevereiro e julho de 2015, os dados foram tabulados e analisados comparando os resultados encontrados nos distintos bairros e a bibliografia referente ao tema.

\section{Resultados e Discussão}

$\mathrm{Na}$ estrutura urbana as condições do ambiente podem e geralmente são influenciadas pela percepção de seus habitantes que estimulam e criam uma imagem ambiental, instituindo culturas e imagens dos locais.
Segundo ressalta Mucelin e Bellini (2008), a vivência cotidiana molda padrões comportamentais habituais. Neste sentido, o morador urbano tem, na maioria das vezes, situações diárias vivenciadas de forma repetitiva, o que produz uma espécie de máscara destas situações no contexto. Isso forma uma imagem perceptiva em dois vieses: de um lado o ambiente urbano legível e perceptível vivenciado; de outro, situações e locais imperceptíveis, ocultos ao julgamento perceptivo.

Os diferentes tipos de poluição bem como a qualidade da água e a leitura dos moradores a respeito destes elementos são apresentados na Figura 2, correspondente ao olhar dos mesmos no cotidiano. 

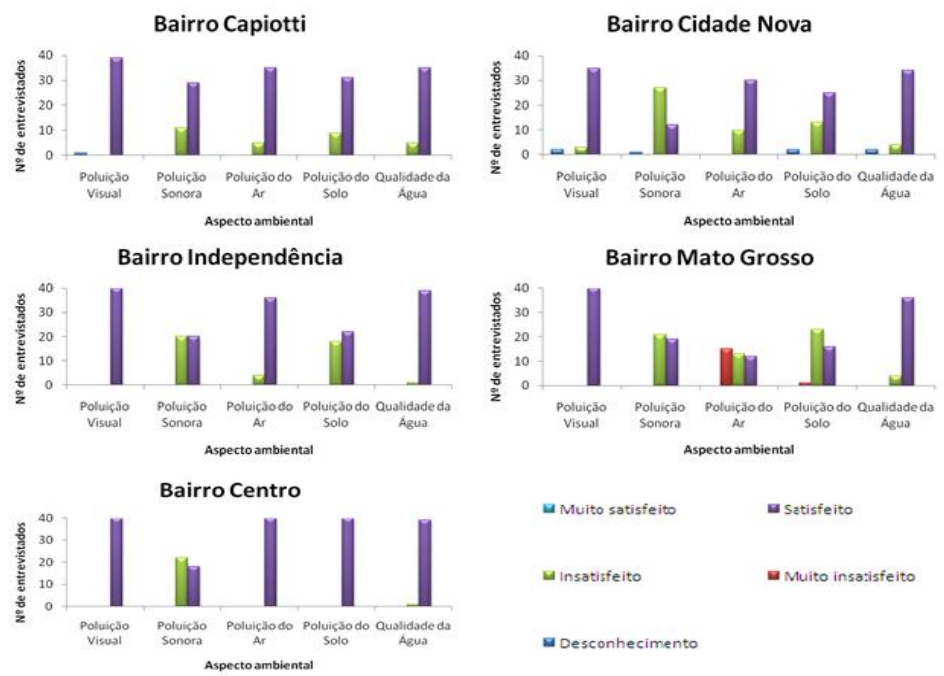

Figura 2 - Grau de satisfação da população quanto ao aspecto poluição e qualidade da água nos bairros estudados no município de São Gabriel, RS

Fonte: Autor, 2015

O aspecto poluição visual foi caracterizado como satisfatório pela maior parte dos entrevistados nos cinco bairros analisados. Este aspecto ambiental, comum em grandes cidades e com consequências severas, não ocasiona problemas para os moradores dos locais estudados.

Para Castanheiro (2009, p.63) a poluição visual gera desarmonia ou desequilíbrio no meio ambiente artificial (cidade e paisagem urbana), prejudicando o bem estar da população e comprometendo a saúde das pessoas através de efeitos psicológicos difíceis de serem diagnosticados.

No bairro Cidade Nova alguns entrevistados (7\%) apontaram insatisfação devido ao acúmulo de letreiros comerciais, mas nenhum grande problema foi identificado nesta questão. Outdoors, placas luminosas ou qualquer outro tipo de poluição visual, praticamente, inexistem nos bairros, inclusive no bairro Centro, o que gerou quase unanimidade no resultado relacionado a este aspecto.

$\mathrm{O}$ aspecto poluição sonora obteve o maior índice de insatisfação dos entrevistados nos cinco bairros analisados. No bairro Cidade Nova $68 \%$ dos entrevistados demonstraram insatisfação quanto a este aspecto ambiental, seguido de 55\% no bairro Centro,
$52 \%$ no bairro Mato Grosso, 50\% no bairro Independência e 27\% no bairro Capiotti.

A principal reclamação dos entrevistados esta diretamente ligada ao constante tráfego de veículos, a sonorização musical em horários inadequados e a presença de animais de rua, que perturbam os moradores, principalmente, nos bairros mais afastados do centro do município.

Para Lima; Carvalho (2010), a poluição sonora urbana disseminada nas sociedades é resultante da combinação de várias fontes sonoras contribuindo para o surgimento de ambientes desagradáveis.

Dentre as variadas fontes de emissão de poluentes, de origem antropogênica, incluem-se os veículos, atividades de mineração, processamento de metais e usinas de combustão e, também, grande número de processos industriais. De acordo com o último fato citado, destaca-se a poluição do ar no bairro Mato Grosso, com 37\% dos entrevistados muito insatisfeitos, seguido de outros 33\% insatisfeitos. Este resultado está relacionado à presença de um frigorífico próximo ao local, instalado às margens do Rio Vacacaí - principal rio que abastece o município.

Dentre os vários impactos ambientais que este tipo de atividade pode gerar, destaca-se o mau cheiro. Devido à incineração de partes não aproveitáveis do material gerado pela atividade produtiva desta indústria, a 
fumaça oriunda deste processo resulta em desconforto para a população do bairro. Apesar de não se poder afirmar que a fumaça resultante da queima desse material seja poluente, quando lançada no ar, ocasiona constante reclamação devido ao "forte odor", principalmente, em estações quentes do ano.

O abate de espécies animais é realizado para obtenção de carne e de seus derivados, destinados ao consumo humano sendo regulamentado por uma série de normas sanitárias destinadas a dar segurança alimentar aos consumidores destes produtos. Como consequência das operações de abate, originam-se vários subprodutos e/ou resíduos que devem sofrer processamentos específicos relacionados à situação de mercado para os vários produtos resultantes e de logística adequada entre as operações (PACHECO; YAMANAKA, 2006).

Muitos resíduos de frigoríficos, segundo Pacheco; Yamanaka (2006) podem causar problemas ambientais graves se forem gerenciados inadequadamente, pois a maioria é altamente putrescível podendo causar odores se não processada rapidamente em graxarias ou removida para processamento adequado.

De acordo com os dados coletados, o aspecto poluição do solo apresentou significante grau de insatisfação em pelo menos dois dos cinco bairros analisados, sendo o índice do bairro Mato Grosso (58\%) o mais relevante dentre eles, seguido do bairro Independência (55\%), Cidade Nova (33\%), Capiotti $(22 \%)$ e, inexistente no bairro Centro.

Por ser um bairro localizado próximo ao rio, o bairro Mato Grosso sofre com a falta de conscientização por parte da população local e municipal. Segundo os entrevistados, moradores de outras regiões da cidade frequentam o bairro com o objetivo de descartar todo tipo de resíduo no rio. Dentre os resíduos se destacam, principalmente, os que não são transportados pelo serviço de coleta, os que ocupam espaço na maioria das residências ou os que não possuem um serviço ambientalmente correto de descarte, tais como móveis, eletrodomésticos e eletroeletrônicos.
Trabalho realizado por Santos (2014), junto ao Arroio Cadena em Santa Maria (RS), apontou que 72,5\% da população consultada responsabilizaram os moradores de outras localidades por depositarem o lixo no arroio, com relatos da frequência de pessoas que estacionam seus carros próximos às margens e iniciam a deposição clandestina do material, incluindo resíduos de construção, pilhas, baterias e lâmpadas os quais deveriam receber tratamento específico, antes de sua destinação final, além de peças de mobiliário, eletrodomésticos e restos de origem orgânica.

De acordo com $58 \%$ dos entrevistados do bairro Mato Grosso, o problema reside no fato de todo o resíduo transportado, tanto por moradores locais quanto por moradores de outras regiões da cidade, para dentro dos limites do bairro, ficar exposto no solo, por longo período, sem providências. O lixo doméstico dos moradores é frequentemente coletado pelo serviço responsável, mas de acordo com os entrevistados, uma parte do mesmo permanece à margem do rio e em áreas próximas, causando a direta poluição do solo e do lençol freático. Esse fato ocorre, possivelmente, devido ao descaso da população quanto ao descarte correto e a falta de informação referente à preservação do meio ambiente.

A disposição pura e simples de lixo nos diversos ecossistemas existentes no mundo é a técnica de processamento mais antiga empregada pelo homem desde as civilizações primitivas até os dias atuais. Porém, essas práticas, amplamente empregadas, são atualmente condenáveis do ponto de vista ambiental e de saúde pública (FIGUEIREDO, 1995).

Ainda sobre o aspecto poluição do solo, os índices expressos nos outros bairros, apesar de menores, também caracterizam insatisfação por parte dos entrevistados.

Em relação à água, Fracalanza (1996) a considerada um bem econômico porque é finita e essencial para a conservação da vida e do meio ambiente e sua escassez impede o desenvolvimento de diversas regiões, na medida em que, além da necessidade humana, 
é essencial no processo produtivo. Do ponto de vista de recurso ambiental pode contribuir para a degradação da qualidade ambiental que afeta, direta ou indiretamente, a saúde, a segurança e o bem-estar da população; as atividades sociais e econômicas; a fauna e a flora; as condições estéticas e sanitárias do meio e a qualidade dos recursos ambientais.

Referente à qualidade da água, o estudo apontou um alto índice de satisfação dos entrevistados, com $98 \%$ de satisfação nos bairros Centro e Independência, seguidos de $90 \%$, Mato Grosso, $88 \%$, Capiotti e $85 \%$ no bairro Cidade Nova. Estes resultados refletem as ações da nova prestadora do serviço de abastecimento que, apesar de estar se adaptando aos novos procedimentos de captação e tratamento, tem possibilitado uma eficiente distribuição do recurso para a população do município.
Sob a perspectiva ambiental, Gomes e Soares (2003) salientam que a qualidade ambiental tem, em parte, referência à percepção humana, podendo ser subjetiva, na medida em que a organização dos elementos naturais e artificiais, compostos de forma distinta de acordo com o lugar, reflete no gosto ou repúdio ao ambiente por parte dos indivíduos.

Suhugusoffet e Piliackas (2007) definiram ação antrópica como qualquer atividade humana que, de alguma forma, interfira nos mecanismos naturais de funcionamento de uma unidade ecológica ou ecossistema. De acordo com esse parâmetro, outros aspectos antrópicos estudados demonstraram dados importantes para caracterizar as questões ambientais vigentes nos locais.
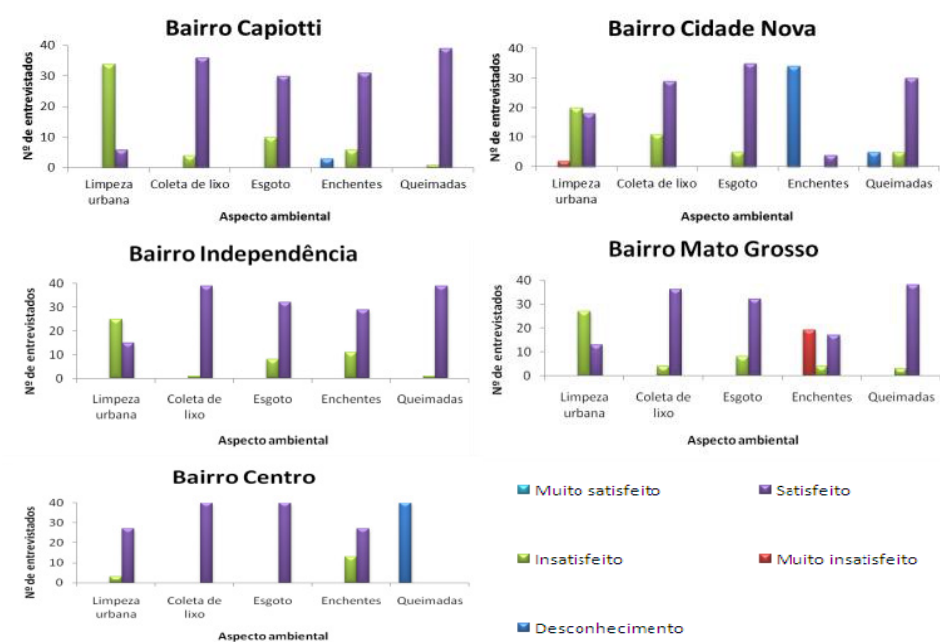

Figura 3 - Grau de satisfação da população quanto a aspectos antrópicos nos bairros estudados no município de São Gabriel, RS.

Fonte: Autor, 2015

Referente ao aspecto limpeza urbana, os índices negativos resultantes da opinião dos entrevistados nos cinco bairros estudados demonstram a insatisfação dos mesmos sob este aspecto. O bairro Capiotti apresentou o maior índice de insatisfação (85\%), seguido do Mato Grosso (67\%), Independência (62\%), Cidade Nova (50\%) e Centro (32\%).

A maioria dos entrevistados, nos bairros Capiotti e Independência, aponta que o principal problema reside na falta de prestação, por parte da administração do município, de serviços básicos de limpeza urbana, como poda de árvores, demarcação de meio-fio, limpeza de bocas de lobo e recolhimento de resíduos específicos oriundos da limpeza de interiores de quintais.

De acordo com os moradores entrevistados nestes bairros, esse tipo de resíduo permanece sobre as vias públicas à espera de recolhimento, o que nem sempre acontece de forma breve, mesmo com informações e solicitações à prefeitura do município, o problema persiste.

Referente ao mesmo aspecto, para os moradores do bairro Mato Grosso, o serviço de limpeza urbana não 
ocorre com frequência, expondo os resíduos dispensados, tanto pela população local quanto municipal, por longos períodos.

De acordo com $50 \%$ dos entrevistados do bairro Cidade Nova que caracterizaram este aspecto como negativo, a insatisfação pelo problema está, também, diretamente ligada à frequência do serviço de limpeza urbana no local.

É importante observar que a questão proposta na pesquisa faz menção à "limpeza de ruas, bocas de lobo e sarjetas", um aspecto da limpeza urbana que, neste estudo, exclui a coleta, ao transformá-la em uma questão única de análise.

A limpeza urbana está, intrinsecamente, ligada à coleta de lixo, aspecto que obteve alto grau de satisfação nos cinco bairros estudados.

Importante ressaltar dois pontos relevantes relacionados à limpeza urbana e à coleta de resíduos. Primeiro, a empresa coletora de lixo presta serviço eficiente dentro dos limites dos bairros, mas de acordo com políticas internas, não recolhe todo o tipo de resíduo. Segundo, uma empresa terceirizada de reciclagem atende os bairros e recolhe resíduos recicláveis, tais como garrafas pet, alumínio e papelão. Esse serviço se torna cada vez mais importante, pois desperta a consciência ambiental da população que passa a dar importância à preservação do meio ambiente por meio da reciclagem do lixo.

O lixo tem sido um problema recorrente em todo o país, agravado acintosamente pelas modalidades inadequadas de disposição final e de confinamento dos rejeitos, aspecto que na voz de inúmeros especialistas, além de gerar sérios desconfortos ambientais e sanitários, pode inviabilizar, até mesmo em médio prazo, a sociedade humana, ao menos tal como a conhecemos (CALDERONI, 2003, p. 25).

Mucelin e Bellini (2007) enfatizam que dentre os impactos ambientais negativos originados a partir do lixo urbano produzido estão os efeitos decorrentes da prática de disposição inadequada de resíduos sólidos em fundos de vale, às margens de ruas ou cursos d'água. Ainda conforme os autores, essas práticas habituais podem provocar, entre outras coisas, contaminação de corpos d'água, assoreamento, enchentes, proliferação de vetores transmissores de doenças, tais como cães, gatos, ratos, baratas, moscas, vermes dentre outros, além da poluição visual, mau cheiro e contaminação do ambiente.

Os índices obtidos demonstraram alto grau de satisfação dos moradores nos bairros amostrados, a saber, bairro Centro, 100\%; Independência, 98\%; Mato Grosso e Capiotti, $90 \%$ e Cidade Nova, $73 \%$, os quais apontaram que a periodicidade do serviço é satisfatória.

Porém, é importante ressaltar que a coleta de lixo não transporta todo o tipo de resíduo tais como, oriundos da limpeza de quintal, resíduos vegetais ou mesmo os que se deterioram nos locais, por inadequação de embalagem, ação de animais de rua ou descaso dos próprios coletadores/catadores. Este dado está diretamente ligado ao aspecto que obteve alto grau de insatisfação dos entrevistados, a limpeza urbana analisado anteriormente.

Importante ressaltar, também, que o município de São Gabriel está se adaptando a coleta seletiva de resíduos. Este tipo de serviço já era oferecido à comunidade por empresa terceirizada, indiretamente ligada à administração municipal, que realizava a coleta em dias específicos em bairros selecionados da cidade. Atualmente, está sendo realizada com mais frequência em todos os bairros do município. De acordo com os entrevistados, os mesmos separam os materiais e os armazenam em locais seguros em suas próprias residências a espera da coleta.

Quanto ao esgoto urbano, de acordo com os dados, a satisfação dos entrevistados nos cinco bairros estudados se caracteriza por $100 \%$ de satisfação no bairro Centro; $88 \%$, Cidade Nova; $80 \%$, Independência e Mato Grosso; e 75\% de satisfação no bairro Capiotti.

Isto reflete o correto planejamento dos bairros que possuem estruturas básicas de saneamento e onde a maior parte do esgoto é canalizado o que evita 
transbordamento em época de chuva, com prejuízo de contaminação de seres humanos e animais ou mau cheiro resultante de bueiros e bocas de lobo.

Este fato é relevante, pois a realidade brasileira demonstra, conforme Silva e Travassos (2008) uma quadro precário com índices da população urbana servida por este serviço na ordem de 48,3\%, ainda com disparidades entre regiões.

Os menores índices de satisfação são demonstrados, respectivamente, pelos bairros Mato Grosso (80\%) e Capiotti (75\%) sendo, no primeiro, importante o destaque de sua localização junto ao principal corpo hídrico do município. Apesar de haver transbordamento em grande parte das vias em época de enchente, os entrevistados consideram o aspecto satisfatório fora desta temporada. Quanto ao bairro Capiotti, o fato se deriva de um curso d'água que corta o bairro não ter sido canalizado devido a questões ambientais. Em épocas mais quentes do ano os moradores são prejudicados pelo mau cheiro e permanência de insetos no local.

Segundo UN-ISDR (2009), as inundações e enchentes são problemas geoambientais derivados de fenômenos ou perigos naturais com caráter hidrometeorológico ou hidrológico, ou seja, aqueles de natureza atmosférica, hidrológica ou oceanográfica.

Seguindo essa definição, o presente estudo aponta os seguintes índices de satisfação quanto a este aspecto nos cinco bairros estudados no município de São Gabriel - RS. São eles: $78 \%$ de satisfação no bairro Capiotti; $73 \%$ no bairro Independência e $65 \%$ no bairro Centro. No bairro Cidade Nova os índices expressaram $85 \%$ de desconhecimento do problema. No bairro Mato Grosso o grau de satisfação "muito insatisfeito", representou $47 \%$ do total de entrevistados.

A desordenada ocupação urbana, o adensamento populacional e as inúmeras atividades antrópicas, resultam em uma maior impermeabilização do solo e num significativo aumento do escoamento superficial, propiciando um maior risco de enchentes.
Nos bairros Capiotti, Independência e Centro, o grau de satisfação dos entrevistados se relaciona diretamente ao fato de que em áreas centrais e/ou áreas que possuem infraestrutura urbana bem desenvolvida - o que é o caso desses bairros -, esse tipo de problema não acontece com frequência devido, justamente, aos sistemas de escoamento e drenagem que são mais eficientes nessas áreas.

Esse fato exclui diretamente o bairro Mato Grosso que, como já mencionado, se encontra na região à margem do rio.

$\mathrm{O}$ alto índice (47\%) de entrevistados muito insatisfeitos, seguido de $10 \%$ insatisfeitos, é reflexo do alto grau de crescimento urbano aliado à falta de planejamento quanto a estruturas que viabilizem uma urbanização eficiente. O bairro Mato Grosso não possui essa estrutura e a não implantação de políticas públicas, ocasiona uma falta de perspectiva por parte da população local quanto a possíveis melhorias.

De acordo com os entrevistados, em época de forte precipitação, a água atinge até metade da altura das residências. Devido à necessidade de liberar parte do grande volume de chuva acumulada nas barragens, a população nem sempre tem tempo hábil para retirar seus pertences das residências, o que acarreta perdas significativas.

A média de tempo de residência dos moradores no local é de 24,5 anos. Este dado evidencia que a população já enfrenta esse tipo de problema há muito tempo.

Em relação ao bairro Cidade Nova, a grande parte dos entrevistados (85\%), desconhece o problema. Isso se deriva do fato de que o bairro em questão possui adequada infraestrutura urbana, com ruas calçadas e esgoto canalizado, evidenciando assim que os sistemas de escoamento e drenagem do bairro atinjam os objetivos propostos.

$\mathrm{O}$ aspecto relacionado às queimadas obteve grau de satisfação positivo na maioria dos locais estudados. Os índices, que demonstram o progresso da urbanização no 
sentido Centro - Bairro no município, apontam saldo positivo de acordo com os resultados da pesquisa, caracterizando os bairros Capiotti e Independência com 98\% de satisfação, seguido dos bairros Mato Grosso e Cidade Nova, respectivamente, com índices que apontam $95 \%$ e $75 \%$ de satisfação e o bairro Centro, onde houve unanimidade no grau de desconhecimento do problema.

Enquanto as queimadas, segundo Coutinho (1990); Fiedler et al. (2006), podem ocorrer no campo por várias causas, tais como o controle de arbustos em pastagens, controle de pragas, e negligência no manejo do fogo em áreas queimadas intencionalmente (limpeza das margens de rodovias e ferrovias), nas cidades, normalmente o fogo é empregado em fundo de quintais, terrenos e áreas abandonadas que servem de depósitos clandestinos de lixo, e lotes sem construção com vegetação de pequeno e médio porte (SILVA; SILVA, 2006).

De acordo com Lopes; Ribeiro (2006), as emissões de material particulado e o monóxido de carbono, originados pelos focos de calor, podem contribuir para a má qualidade do ar e influenciar doenças respiratórias.

Apesar de possuir uma planejada estrutura urbana, no bairro Cidade Nova, em alguns pontos, ainda observa-se a queima de resíduos. Isto se justifica pelo aspecto cultural, comum em cidades menores, porém a tendência é a redução, pois a estrutura urbana do bairro inviabiliza a frequência deste tipo de atividade. Logo, este aspecto ambiental se descaracteriza como um problema em busca de solução, pois não há espaço e nem condições para que se realizem queimadas dentro do território urbano.

Outros temas relacionados à satisfação dos moradores quanto aos aspectos ambientais merecem ser informados devido a sua importância dentro do contexto do presente estudo e dizem respeito ao desmatamento, as políticas públicas e a ocupação irregular.

Referente ao aspecto desmatamento, enquanto o bairro Centro obteve $100 \%$ de desconhecimento relacionado à questão, os bairros Independência e Mato Grosso obtiveram $100 \%$ de satisfação, seguidos do bairro Capiotti (90\%) e Cidade Nova (80\%).

As mudanças na cobertura do solo são definidas pelas relações homem-natureza que se dão ao longo do tempo, transformando antes uma paisagem natural em uma paisagem artificial com componentes naturais (MERTENS; LAMBIN, 2000).

Para Santos (1988, p.71) se um lugar não é fisicamente tocado pelas mãos do homem, ele, todavia, é objeto das preocupações e intenções econômicas e políticas.

Relativo ao aspecto desmatamento, o mesmo se dá devido ao crescimento demográfico e populacional que origina uma expansão territorial que não respeita os limites do que é permitido dentro do contexto urbano, resultando num desequilíbrio em todas as áreas de desenvolvimento.

As ações humanas no ambiente configuram-se, portanto, como ações socioeconômicas, políticas e culturais, inseridas tanto em um contexto global como local, e o desmatamento, por sua vez, é resultado de diversos fatores distintos que estão presentes em diferentes escalas, entendendo-se assim, que se trata de uma questão complexa e multifacetada.

De acordo com a análise dos dados coletados, o aspecto políticas públicas obteve unanimidade no resultado relacionado ao índice de insatisfação nos bairros Capiotti, Centro, Independência e Mato Grosso, seguido do bairro Cidade Nova (83\%).

Segundo os moradores entrevistados na pesquisa, esse alto índice de insatisfação relacionado ao tema deriva do fato de não haver nenhum tipo de política vigente que objetive uma melhoria no aspecto ambiental dos bairros. Ainda de acordo com os mesmos, agentes da administração não consultam a população acerca dos problemas urbanos, incluindo os ambientais, que acometem os bairros do município e que dificilmente os frequentam fora do período eleitoral - o que evidencia 
um descaso com as necessidades gerais de toda a comunidade.

Segundo Abreu (2011), Política Pública é a expressão do poder público em face dos problemas e dos diferentes atores que compõem o cenário e sua intenção de dar respostas ao papel do Estado na sua relação com os anseios da sociedade. Para Silva; Souza-Lima, 2010, políticas públicas definem-se como todas as ações do governo relacionadas às atividades diretas de produção pelo próprio Estado cuja influencia recai nas realidades sociais, econômicas, ambientais, especiais e culturais.

As diretrizes da Política Nacional do Meio Ambiente - PNMA foram formuladas em normas e planos, destinados a orientar a ação dos Governos da União, dos Estados, do Distrito Federal, dos Territórios e dos Municípios no que se relaciona com a preservação da qualidade ambiental e manutenção do equilíbrio ecológico, segundo os princípios estabelecidos no art. $2^{\circ}$ desta Lei. Todavia, está função do PNMA é regulada pela Constituição, no art. 23, sendo competência comum da União, dos Estados, do Distrito Federal e Municípios proteger o meio ambiente e combater a poluição em qualquer de suas formas (BRASIL, 1988).

Relacionado ao aspecto ocupação irregular, houve unanimidade no índice de desconhecimento relacionado ao tema por parte de todos os moradores entrevistados nos cinco bairros do município.

A busca incessante por espaços para habitação e trabalho contribuiu para que aumentassem, de forma acentuada, os conflitos sociais nas cidades, locais onde a tradição de competição entre classes sociais está bastante presente, reforçando a ocupação desordenada de áreas pouco adequadas à construção de moradias e onde o formal e informal disputam espaço no meio físico (CAMPOS, 2005).

Este aspecto ambiental obteve certa contrariedade, pois $10 \%$ dos entrevistados, do bairro Mato Grosso, informaram que os terrenos onde se localizam seus domicílios não são regularizados. Este tema pode ter sido omitido pela maior parte da comunidade entrevistada com o objetivo de preservar a identidade do ocupante irregular e, assim, evitar intervenções legais que certamente alterariam a harmonia do local e da comunidade.

Em relação a este bairro foram elaboradas questões específicas quanto ao conhecimento de aspectos relativos ao rio que dinamizam a importância da questão ambiental nessa área.

Dos cinco locais estudados, o bairro Mato Grosso é o único que se localiza às margens do principal rio que abastece o município de São Gabriel, o Rio Vacacaí - fato este que já evidencia a importância do local sob a ótica ambiental.

Incapaz de suprir a necessidade da população por bem estar e qualidade de vida, equilibrando estas necessidades com a preservação, o bairro Mato Grosso mantém desníveis significativos quanto à qualidade ambiental. De acordo com os aspectos relatados no presente estudo, evidenciam-se os inúmeros impactos negativos oriundos desta falta de planejamento, principalmente, ligados à questão relacionada à preservação das Áreas de Preservação Permanente, as APP.

$\mathrm{O}$ rápido crescimento das áreas urbanas associado à politicas ineficientes de uso e ocupação do solo e à especulação imobiliária vem provocando a ocupação de áreas que deveriam estar protegidas ambientalmente. Dentre os diversos impactos sociais e ambientais destacam-se os relacionados à ocupação populacional e crescimento urbano em direção a áreas inadequadas, como as Áreas de Preservação Permanente (APP).

O texto do Novo Código Florestal (Lei Federal $\mathrm{n}^{\mathrm{o}}$ 12.651/2012) define as APP como área protegida, coberta ou não por vegetação nativa, com a função ambiental de preservar os recursos hídricos, a paisagem, a estabilidade geológica e a biodiversidade, facilitar o fluxo gênico de fauna e flora, proteger o solo e assegurar o bem-estar das populações humanas (BRASIL, 2012). 
De acordo com essa definição, as áreas de preservação permanente, como é o caso das margens de rios, deveriam ser protegidas, mas isto não ocorre de forma eficiente no bairro e o descaso por ações que objetivem preservar estas áreas são questões que ainda permanecem sem resposta.

Conforme Macedo e Magalhães Jr. (2011, p.60) os paradigmas das intervenções estruturais e da descaracterização dos cursos d'água urbanos pela poluição e artificialização, levou a sociedade a percebêlos não mais como artérias hídricas, mas como transportadores de dejetos, disseminadores de doenças e ameaças de inundações.

O Novo Código Florestal vale-se como instrumento adequado para o ordenamento territorial e planejamento da paisagem. Os problemas atuais de uso do solo devem-se à inobservância de regras, e não a uma possível ineficácia do Código Florestal de 1965. Essa mesma atitude de descaso gera a perspectiva de cenários futuros ainda mais críticos, notadamente os associados aos desastres naturais. Cabe citar que boa parte das cidades brasileiras apresenta problemas de enchentes e inundações, sendo as das regiões metropolitanas as que apresentam situações de risco mais graves, em decorrência do grande número de núcleos habitacionais de baixa renda que ocupam terrenos marginais de cursos d'água (BRASIL, 2007).

As questões elaboradas para analisar os aspectos ambientais relacionados ao rio obtiveram dados importantes que caracterizam os problemas do entorno e, assim, permitem elaborar possíveis soluções para mitigálos.

A Figura 4 apresenta o grau de conhecimento relacionado às questões propostas relativas à localização do bairro Mato Grosso quanto ao Rio Vacacaí.

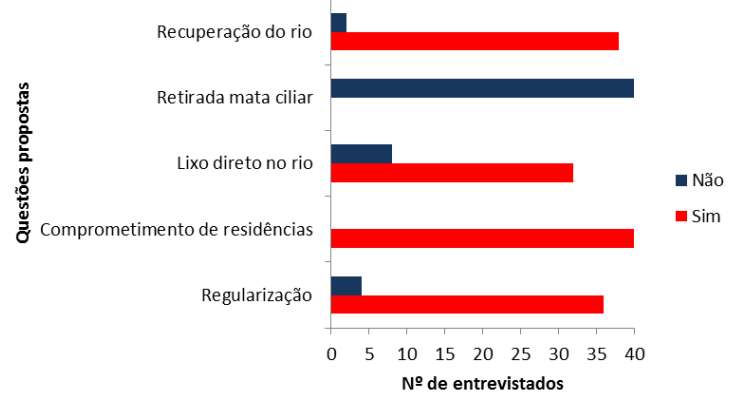

Figura 4 - Grau de conhecimento dos moradores do bairro Mato Grosso quanto às questões propostas relativas à localização do bairro e a proximidade do Rio Vacacaí, São Gabriel, RS Fonte: Medeiros, 2015

Observou-se que o local se caracteriza por ocupações irregulares, pois se encontram em área ambientalmente frágil e ambientalmente protegida.

Quanto ao aspecto comprometimento de residências, com ênfase à época de cheia, a totalidade dos entrevistados é unânime em afirmar que nestes períodos são obrigados a deixar suas residências em busca de locais seguros devido aos problemas gerados como a dificuldade de acesso, veiculação de doenças, perda de mobiliário entre outros.
Ficou reiterado o fato do rio e suas margens servirem de depósito de resíduos oriundos do local mas, principalmente, de outras localidades.

Em relação à retirada de mata ciliar, os entrevistados apontaram unanimidade no que diz respeito ao desconhecimento do fato, apesar de ser visível a inexistência de vegetação em vários pontos da margem.

As matas ciliares, segundo Ferreira (2004), atuam como barreira física, regulando os processos de troca entre os ecossistemas terrestres e aquáticos, 
favorecendo a infiltração da água no solo e reduzindo significativamente a contaminação dos cursos d'água. A degradação das matas ciliares contribui para o assoreamento dos cursos d'água, elevação da turbidez da água e erosão das margens dos cursos d'água, transportando substâncias poluidoras como defensivos e fertilizantes agrícolas. Uma das principais causas do assoreamento é a retirada da vegetação natural das Áreas de Preservação Permanente (NOWATZKI et al., 2010).

Segundo Crestana et al. (1993), apesar de o Brasil possuir uma legislação ambiental rigorosa e ampla, os órgãos responsáveis não se têm mostrado ágeis no cumprimento de suas obrigações. Este fato permanece atual e relevante no que diz respeito ao cumprimento da legislação no país.

A ausência de procedimentos uniformizados e da infraestrutura necessária para se apurar com o devido rigor as agressões ao meio ambiente, no bairro, dificultam o controle nessas áreas, apesar da significativa importância da mata ciliar relacionada à conservação e preservação dos cursos d'água.

Apesar de todas as questões versarem sobre problemas ambientais relacionados à proximidade do bairro com o rio, os moradores não deixam de acreditar na possível recuperação do mesmo. A questão relacionada à esperança de recuperação obteve 95\% de afirmação por parte dos moradores entrevistados.

Segundo os mesmos, há décadas passadas, o Rio Vacacaí era utilizado para lazer dos moradores do município e região e este aspecto, quando mencionado, permite perceber nos moradores a crença positiva de que, em algum tempo futuro, o rio possa ser recuperado e volte a trazer bem estar e qualidade de vida a toda a população do município de São Gabriel, RS.

\section{Conclusões}

A percepção por parte da população de que o desequilíbrio de determinados fatores em um ecossistema resulta em questões que precisam ser discutidas e solucionadas, implica definir os níveis de qualidade ambiental em determinada área urbana.

Este trabalho abordou a dinâmica da percepção diretamente associada à qualidade ambiental urbana no município de São Gabriel - RS, ao analisar aspectos como poluição, qualidade da água, limpeza urbana, ocupação irregular, políticas públicas entre outros.

De acordo com os duzentos moradores entrevistados para o presente trabalho, pode-se observar que, apesar da maioria dos aspectos ambientais propostos obter grau positivo de satisfação, a falta de aplicação de políticas públicas municipais, relacionadas, principalmente, ao aspecto ambiental, gerou o maior grau de insatisfação dos entrevistados em todos os locais estudados.

As manifestações relacionadas à percepção caracterizam a importância dada às questões ambientais pela sociedade no que se refere ao bem estar e qualidade de vida. A partir do conhecimento e entendimento dos fatores que desequilibram a harmonia do ambiente, a sociedade pode exigir dos órgãos públicos medidas que beneficiem a melhoria do aspecto ambiental dentro de suas áreas. Este conhecimento implica em transformação cultural, pois uma sociedade consciente se permite questionar sobre assuntos que lhe são pertinentes e encontrar, junto ao poder público, soluções aplicáveis para a defesa de questões vinculadas ao interesse geral.

A informação e a educação ambiental são ferramentas eficazes para que os atores sociais se conscientizem de seus papéis e possam exigir providências às autoridades num processo de coresponsabilização e participação comunitária.

Atualmente, o principal desafio que se impõe às cidades é que as mesmas criem as condições necessárias para assegurar uma qualidade de vida que possa ser considerada aceitável à população e que possam agir, preventivamente, a fim de evitar a continuidade dos níveis de degradação ambiental. 


\section{Referências}

Abreu; L. E. de (Org.). As Políticas Públicas e Suas Narrativas. Brasília: Ipea, 2011.

Alirol, P. Como Iniciar um Processo de Integração. In: Vargas, H. C., Ribeiro, H. (orgs.). Novos Instrumentos de Gestão Ambiental Urbana. Editora da Universidade de São Paulo-EDUSP. São Paulo-SP. p. 21-42. 2001.

Barbisan, A. O; Pandolfo, A; Reinehr, R; Martins, M.S; Pandolfo, L. M; Guimarães, J; Rojas, J. W. J. R. Técnica de valoração econômica de ações de requalificação do meio ambiente: aplicação em área degradada. Eng. Sanit. Ambient. [online]. 2009, vol.14, n.1, pp. 119-128. ISSN 1413-4152. Disponível em: $<$ http://www.scielo.br/pdf/esa/v14n1/v14n1a13.pdf $>$. Acesso em: 16 Fev. de 2015.

Brasil; Constituição da República Federativa do Brasil. Brasília, 1988. Senado Federal. Disponível em: https:// www.presidencia.gov.br/casacivil/site/static/ le.htm. Acesso em : 15.jun.2015.

; Ministério das Cidades / Instituto de Pesquisas Tecnológicas (IPT) Mapeamento de Riscos em Encostas e Margem de Rios. Carvalho, C. S.; Macedo, E. S. de; Ogura, A. T. (Orgs.). Brasília: Ministério das Cidades; Instituto de Pesquisas Tecnológicas - IPT, 2007. 176 p. Disponível em: http://www.cidades.gov.br/images/ stories/ArquivosSNPU/Biblioteca/PrevencaoErradicaca o/ Livro_Mapeamento_Enconstas_Margens.pdf. Acesso 19 ago 2015 .

; Presidência da República. Lei 12.651, de 25 de maio de 2012, Brasília. Disponível em: https:// www.planalto.gov.br/ccivil_03/_ato2011-

2014/2012/lei/ 112651.htm Äcesso em: 20 out. 2015.

Brilhante, O. M. Environmental Management in Middle and Small Cities in Latin America. In: Internacional Conference on Water and Sanitation. Colombia, 2000.

Calderoni, S. Os bilhões perdidos no lixo. 4. ed. São Paulo: Humanitas/ FFLCH-USP, 2003. p. 25.

Campos; A. C. O Estado e o Urbano: os Programas de Construção de Conjuntos Habitacionais em Aracaju. Revista do Instituto Histórico e Geográfico de Sergipe. Aracaju, v.1, p.199-222, 2005.

Carvalho, D, S. Percepção da qualidade ambiental em Aveiro: estudo das reclamações ambientais. 2007. 217 f. Dissertação (Mestrado em Gestão e Políticas Ambientais) - Universidade de Aveiro, Aveiro, Portugal.

Castanheiro, I. C. A poluição visual: formas de enfrentamento pelas cidades. Revista Internacional de Direito e Cidadania, n. 4, p. 63-78, junho/2009.

Crestana, et al.: Florestas: sistemas de recuperação com essências nativas. Campinas: Coordenadoria de Assistência Técnica Integral. 1993. 60p.
Del Rio, V. (1999) - Cidade da Mente, Cidade Real: Percepção e Revitalização da Área Portuária do RJ. In: Del Rio, V.; Oliveira, L. (org.), Percepção Ambiental: A Experiência Brasileira, pp.3-22, Ed Studio Nobel, São Carlos, SP, Brasil. ISBN: 8528604411.

Faggionato, S. Percepção ambiental, 2007. Disponível em:

$<$ http://educar.sc.usp.br/biologia/textos/m_a_txt4.html $>$ . Acesso em: 20 jan. 2015.

Fernandes, F. A. dos S. O poema imperfeito: crônicas de Biologia, conservação da natureza, e seus heróis. 2. ed. Curitiba: UFPR, 2004.

Ferreira, D. A. C.; Dias, H. C. T.; Situação atual da mata ciliar do ribeirão São Bartolomeu em Viçosa, MG. Revista Árvore, Viçosa, MG, v. 28, n. 4, p. 617-623, 2004.

Fiedler, N.C.; Merlo, D. A.; Medeiros, M.B. (2006). Ocorrência de incêndios florestais no Parque Nacional da Chapada dos Veadeiros, Goiás. Ciência Florestal, v. 16 , p. 153-161.

Figueiredo, P. J. M. A sociedade do lixo: os resíduos, a questão energética e crise ambiental. Piracicaba: Unicamp, 1995. 240p.

Fracalanza, A. P., 1996. 100p. Programa de Despoluição do Rio Tietê: uma análise de concepções no tratamento de recursos hídricos e da participação de diferentes atores. Dissertação de Mestrado, Campinas, São Paulo, Instituto de Filosofia e Ciências Humanas, Universidade Estadual de Campinas.

Gomes, M. A.; Soares, B. R. A vegetação nos centros urbanos: considerações sobre os espaços verdes em cidades médias brasileiras. Estudos Geográficos, Rio Claro, 1(1): 19-29, Junho, 2003.

Lima, A. G, da M.; Carvalho, R, G. Poluição sonora no meio ambiente urbano- Caso Centro de Mossoró, Rio Grande do Norte, Brasil. Rede-Revista Eletrônica do Prodema, Fortaleza, v.5,n.2, p.69-87, 2010.

Lopes, F. S.; Ribeiro, H. Mapeamento de internações hospitalares por problemas respiratórios e possíveis associações à exposição humana aos produtos da queima da palha de cana-de-açúcar no estado de São Paulo. Revista Brasileira de Epidemiologia, São Paulo, v. 9, n. 2, p. 215-225, trimestral, 2006.

Macedo, D. R.; Magalhães Jr, A. P. Percepção social no programa de restauração de cursos d'água urbanos em Belo Horizonte. Sociedade \& Natureza, Uberlândia, v.23, n.1, p.51-63, abr. 2011.

Mazzeto, F. A. P. Qualidade de vida, qualidade ambiental e meio ambiente urbano: breve comparação de conceitos. In: Sociedade e Natureza (Revista do Instituto de Geografia da UFU). Uberlândia: EDUFU, Ano 12, n 24 - Jul/dez 2000, p. 21-31.

Mertens, B.; Lambin, E. F. Land-cover-change trajectories in southern cameroon. Annals of the 
Association of American Geographers, Washington, v. 90, n. 3, p. 467-494, 2000.

Mucelin, C. A.; Bellini, L. M. Lixo e impactos ambientais perceptíveis no ecossistema urbano. Sociedade \& Natureza. Uberlândia, n. 20, p. 111-124, jun. 2008.

, C. A.; Bellini, L. M. Percepção ambiental em ecossistema urbano. In: Congresso de Ecologia do Brasil, 8. Anais... Coxambu - MG: UTFPR, UEM, 2007. Disponível em $<$ http://www.sebecologia.org.br/viiiceb/pdf/291.pdf $>$. Acesso em: $29 \mathrm{de}$ abril 2015.

Nowatzki, A.; Santos, L. J. C.; Paula, E. V. Utilização do SIG na delimitação das áreas de preservação permanente (APP's) na Bacia do Rio Sagrado (Morretes/PR). Sociedade e Natureza, Uberlândia, v. 22, n. 1, p. 107-120, 2010.

Pacheco, J. W.; Yamanaka, H.T. Guia Técnico Ambiental de abates (bovino e suíno). São Paulo: CETESB, 2006.

Rodrigues, A. M. Produção e Consumo do e no Espaço: Problemática ambiental urbana. São Paulo: Editora Hucites, 1998.

Sachs, I. Rumo à ecossocioeconomia: teoria e prática do desenvolvimento. São Paulo: Cortez, 2007.

Santos, M. Metamorfoses do espaço habitado. São Paulo: Hucitec, 1988. v. 4, 136 p.

Santos, N. R. Z. dos. O difícil convívio arroio $\mathrm{x}$ lixo $\mathrm{x}$ moradores. In: Congresso Nacional de Gestão Ambiental, 5. Belo Horizonte, 2014. Anais... Abeas, 2014.

Silva, A. S; Silva, M. C. (2006). Prática de queimadas e as implicações sociais e ambientais na cidade de Araguaina-TO. Caminhos de Geografia, v. 7, n. 18, p. 8-16.

Silva, C. L. da; Souza-Lima, J. E. de (Org.). Políticas Públicas e Indicadores para o Desenvolvimento Sustentável. São Paulo: Saraiva, 2010.

Sousa e Silva, L; Travassos, L. Problemas ambientais urbanos: desafios para a elaboração de políticas públicas integradas. Cadernos Metrópole, n. 19 p. 2747, 10 sem. 2008.

Tuan, Y. Espaço e lugar: a perspectiva da experiência. São Paulo: Difel, 1983. 250 p.

Suhugusoff, V. G., Piliackas, J. M. Breve histórico da ação antrópica sobre os ecossistemas costeiros do Brasil, com ênfase nos manguezais do estado de São Paulo. Integração, Butantã, n. 51. p. 343-351, out. 2007.

Un-Isdr - United Nations Internacional Strategy for Disaster Reduction. 2009. Terminology on Disaster Redution. Disponível em: http://www.unisdr.org. Acesso em: 18 agosto de 2015. 